Research Article

\title{
Novel Runner Configuration of a Gravitational Water Vortex Power Plant for Micro Hydropower Generation
}

\author{
Aamer Sharif ${ }^{1, *}$, Muftooh Ur Rehman Siddiqi ${ }^{1}$ and Riaz Muhammad ${ }^{2}$
}

${ }^{1}$ Department of Mechanical Engineering CECOS University of IT and Emerging Science, Peshawar, Khyber Pakbtunkhwa, Pakistan ; ${ }^{2}$ University of Bahrain, Bahrain.

\begin{abstract}
The demand for renewable energy is increasing in developing countries. In developing countries like Pakistan renewable energy such as micro hydropower has come to be one of the most dominant sources of energy for its low cost, user- friendly, reliable and clean generation of electricity. Gravitational water vortex power plant is certainly one of such low head hydro turbines in which the potential energy of free surface flowing water is converted into kinetic energy through vortex turbine that tangentially passing the water into the basin, which forms a powerful water vortex. This study is the experimental analysis of novel runner which has the ability to maximize output power and efficiency. Computational fluid dynamic (CFD) is carried out on novel runner and ANSYS (CFX) was used to numerically analyze the water flow over the channel and formed water vortex in a conical basin. The experimental analysis was absorbed by measuring the rotational speed (rpm), torque, output power and efficiency of the vortex turbine. The result showed that efficiency $(52.54 \%)$ is maximum at median rotational speed and median torque applied on shaft. Also water vortex height and output power decreased as torque increased on turbine shaft.

Received: January 02, 2020; Accepted: May 13, 2020; Published: June 30, 2020

*Correspondence: Aamer Sharif, Department of Mechanical Engineering CECOS University of IT and Emerging Science Peshawar, Khyber Pakhtunkhwa, Pakistan; Email: aamirsharif120@gmail.com

Citation: Sharif A., M.U.R. Siddiqi and R. Muhammad. 2020. Novel runner configuration of a gravitational water vortex power plant for micro hydropower generation. Journal of Engineering and Applied Sciences, 39(1): 87-93.

DOI: http://dx.doi.org/10.17582/journal.jeas/39.1.87.93

Keywords: GWVPP, GWVPT, CFD, BHP, IHP, ANSYS (CFX), Renewable energy
\end{abstract}

\section{Introduction}

G ravitational water vortex power plant is extremely J low head hydropower that could perform in a low head of $0.7-3 \mathrm{~m}$ same like traditional low head hydropower turbines used for the generation of renewable energy absorbed by high quality friendly environmental yield Dhakal et al. (2015). Franz Zotloterer Austrian Engineer first invented this power generating plant while he was studying out a green manner to aerate the water. In traditional hydropower development the gravitational water vortex power plant is a landmark because previously energy was needed to tolerate water, but now this technology makes use of water aeration manner to produce electricity. Wanchat and Suntivarakorn (2012). Water passes tangentially into a round cylindrical basin through a large inlet channel which formed an effective water vortex; an exit hole through which the water finds its outlet is made at the bottom of the conical or cylindrical basin Mulligan and Hull (2010). The vortex turbine does not performed work on pressure differential but it operates through the dynamic force of the vortex across the turbine runner to create the torque on the output shaft; not only this low head hydropower produces energy, it also aerates the water Rahman et al. (2017). Restrained worked should performed on the development of GWVT. 
The first primary invention of the GWVPP was in 2004 so researchers have paid a few attentions to the development and optimization of the basin and blade. Experimentally validated that for the same flow rate and same head conditions the output power produced by GWVT is greater than any other low hydropower turbine Venukumar (2013). Completed an in-depth experimental analysis to investigated the effects of various inlet conditions, size, length and quantity of blades on turbine torque, rotational speed and vortex height Power et al. (2016). Used a CFD analysis which might be experimentally validated to numerically analyze the water vortices absorbed in three distinct sorts of basin geometries Wanchat and Suntivarakorn (2012), Wanchat et al. (2013). Used a CFD simulation to numerically analyzed the most reliable water vortex height configuration of a GWVT Shabara et al. (2015). The previous studies have noted that devaluation in efficiency of a GWVT occurred when vortex turbine blades is increased from 6 to 12. Dhakal et al. (2014) However, the efficiency rises when the quantity of blade is expanded from 2 to 4 Power et al. (2016). Centrifugal, Francis and impulse paddle-type configuration blades were examined for the design of the vortex turbine blades to absorbed overall performance of GWVT (Nishi and Inagaki, 2017; Gheorghe-Marius and Tudor, 2013; Power et al., 2016). The numerical and experimental analysis gives a positive restriction on increasing the turbine performance with baffled plates Wichian and Suntivarakorn (2016). The performance of the vortex turbine increased when curved blades designed in a vertical and horizontal plane (Chattha et al., 2017; Khan et al., 2018; Dhakal et al., 2015). The choice of the blade materials is equally essential and it's been mentioned that aluminum blades supplied greater efficiency than steel because of its light-weight Wichian and Suntivarakorn (2016). Increase of 6\% performance is stated by adding a further runner to a current runner on same shaft Gautam et al. (2016). Experimental study on multi-staging of GWVT in a conical basin was carried out to improve output and efficiency of GWVPP Rizwan et al. (2020).

\section{Materials and Methods}

GWVPT setup particularly includes a round basin and a turbine. The basin is a massive tank of the cylindrical or conical cross-section to achieved a synthetic gravitational water vortex. The turbine includes a runner. Two fluid domain were created using CAD software, Solid works. A rotating domain which the turbine model rotates in and stationary domain which the water flow as shown in Figure 2.

\section{Mathematical model and governing equations}

The free surface air-core vortex became fashioned due to the interface among water and air ( $\mathrm{Li}$ et al., 2008; Wanchat and Suntivarakorn, 2012). Therefore, the CFD analysis was examine, in which two fluids water and air occupy the identical domain and velocity fields which absorbed through multiphase Eulerian fluid technique. The pressure was set to $(1 \mathrm{~atm})$ and temperature of the domain becomes set to $25^{\circ} \mathrm{C}$. The governing equations for a steady, incompressible, viscous, and turbulent vortex flow have been the continuity and the Navier-Stokes equations Wang et al. (2010).

$$
\begin{gathered}
\frac{\partial V_{r}}{\partial_{r}}+\frac{V_{z}}{\partial_{z}}+\frac{V_{r}}{r}=0 \\
\partial V_{r} \frac{\partial V_{\theta}}{\partial_{r}}+V Z \frac{\partial V_{\theta}}{\partial_{z}}+\frac{V_{r} V_{\theta}}{r}+\frac{V_{r} V_{\theta}}{r}=V\left(\frac{\partial^{2} V_{\theta}}{\partial r^{2}}+\frac{\partial V_{\theta}}{r \partial r}-\frac{V_{\theta}}{r^{2}}+\frac{\partial^{2} V_{\theta}}{\partial z^{2}}\right) \\
V_{r} \frac{\partial V_{r}}{\partial_{r}}+V Z \frac{\partial V_{r}}{\partial_{z}}-\frac{V^{2} \theta}{r}+\frac{\partial_{\rho}}{\rho \partial r}=V\left(\frac{\partial^{2} V_{r}}{\partial r^{2}}+\frac{\partial V_{r}}{r \partial r}-\frac{V_{r}}{r^{2}}+\frac{\partial^{z} V_{r}}{\partial z^{2}}\right) \\
\partial V_{r} \frac{\partial V_{z}}{\partial_{r}}+V Z \frac{\partial V_{z}}{\partial_{z}}+\frac{\partial \rho}{\rho \partial^{z}}=g+V\left(\frac{\partial^{2} V_{z}}{\partial r^{2}}+\frac{\partial V_{z}}{r \partial r}+\frac{\partial^{z} V_{r}}{\partial z^{2}}\right)
\end{gathered}
$$

The following equations were used to measure the various input and output parameters during experimental analysis of GWVPP Khan et al. (2018). If the rotational speed of vortex turbine in revolution per minute (rpm) is $\mathrm{N}$, then the angular velocity can be calculated as:

$$
\begin{gathered}
\operatorname{Angular} \text { velocity }(\omega)=2 \times \pi \times \frac{N}{60} \ldots \\
\text { Torque }=T=r F \quad \ldots(6)
\end{gathered}
$$

If $\mathrm{T}$ is torque, then input and output power can be calculated as follows:

Brake horse power $(B H P)=$ Output power $=T \times \omega$

$$
\begin{array}{r}
\text { Input power }(I H P)=\gamma H Q \\
\text { Efficiency }(\eta)=B H P / I H P \times 100
\end{array}
$$

\section{Numerical model development}

Computational Fluid Dynamic (CFD) is the most competent mechanism for studying the fluid and enhancing turbine efficiency and power output. In this study, CFD simulation has been reported out for water flow in the conical basin where the turbine has 
set at the position of $65 \%-75 \%$ in the conical basin from the top of the basin height to extract output through numerical and experimental method. The design parameters on reduced scale for conical basin as shown in Figure 1 with basin diameter $400 \mathrm{~mm}$, basin height $610 \mathrm{~mm}$, cone angle $23^{\circ}$, canal length $880 \mathrm{~mm}$, canal height $200 \mathrm{~mm}$, canal width $200 \mathrm{~mm}$, notch angle $10^{\circ}$, notch length $480 \mathrm{~mm}$, basin outlet $57 \mathrm{~mm}$ Dhakal et al. (2015).
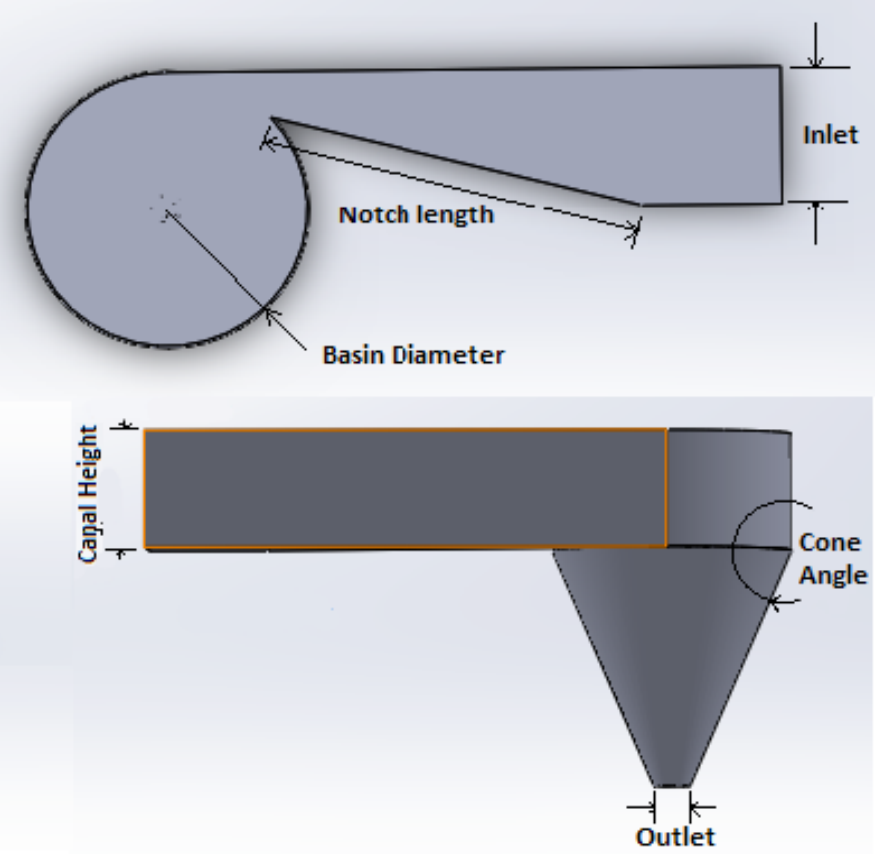

Figure 1: Design of conical basin taken from the study of previous research.

Rotary and stationary domain of GWVPP are as shown in below Figure 2. The mesh independency test was taken on three types of modes coarse, medium and fine also changing the mesh size. The element size for the mesh is 0.001 , and the number of elements used is 657777 . The tetrahedral elements are used for the meshing of the basin. The meshes of the optimized basin and turbine are as shown in Figure 3.

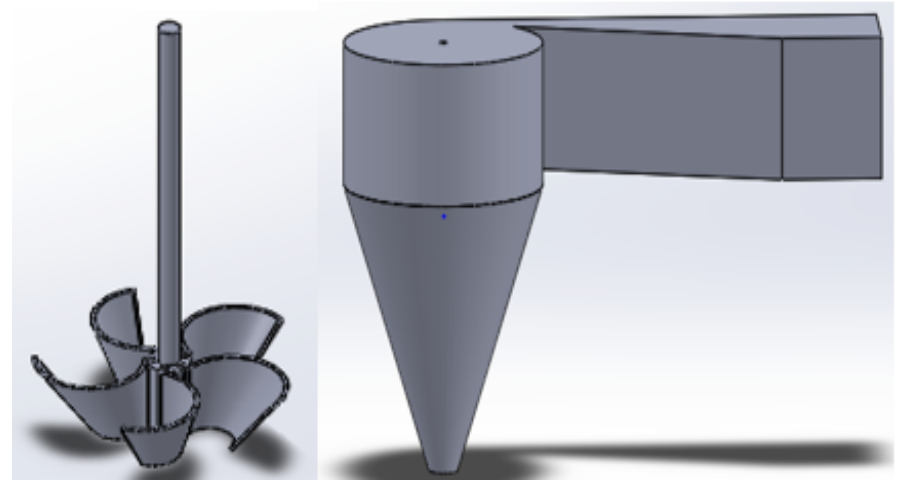

Figure 2: Rotatory and stationary domain.

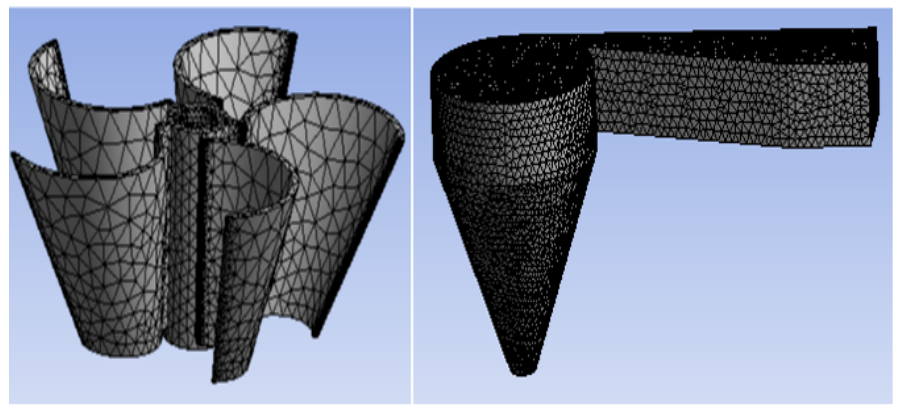

Figure 3: Meshing of rotatory and stationary domain.

Modeling of GWVPP with proposed novel runner as shown in Figure 4. The boundary conditions for proposed novel runner in conical basin as shown in Figure 5.

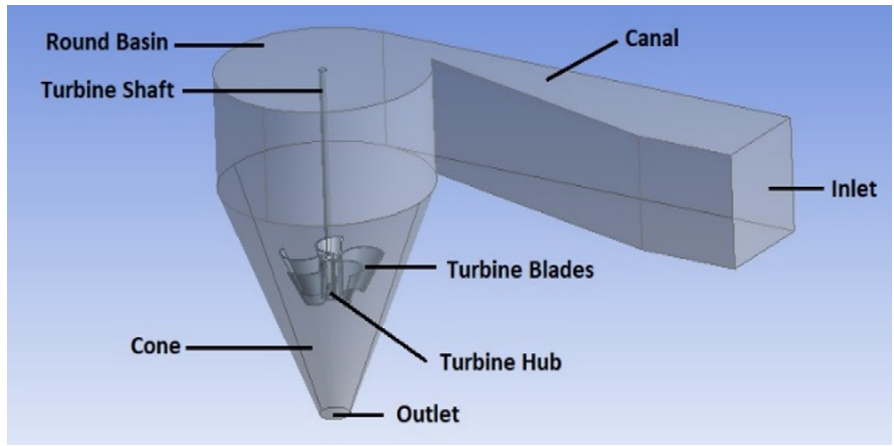

Figure 4: Modeling of GWVPP model with proposed novel runner.

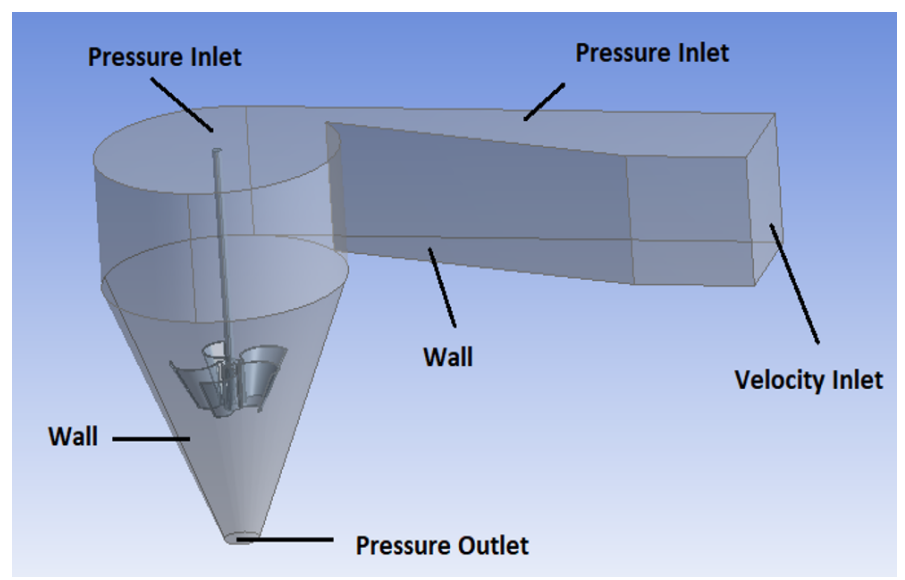

Figure 5: Boundary condition of GWVPP model.

A proposed novel runner model with five blades have diameter of $200 \mathrm{~mm}$, height $67 \mathrm{~mm}$, hub diameter of $30 \mathrm{~mm}$ and blade angle $167^{\circ}$ placed at $65 \%-75$ $\%$ of conical basin from top position as shown in Figure 4 was designed over which CFD analysis is performed as shown in Figure 7. The simulation took one hour and three minute to complete. For the purpose of optimized efficiency, novel runner was designed on CAD software, Solid Work in order to hit the energy of water vortex both in horizontally and vertically as shown in Figure 6. There are different variables examined during the design of the runner of 
GWVPP such as the length and height of blades, the thickness of blade, the inlet and outlet blade angle in both horizontal and vertical plane, the taper angle of the blade, the impact angle of the blade, the number of blades of runner, inner and outer diameter of blades, inner and outer diameter of hub of runner, was taken into consideration to produced more efficiency and output power.

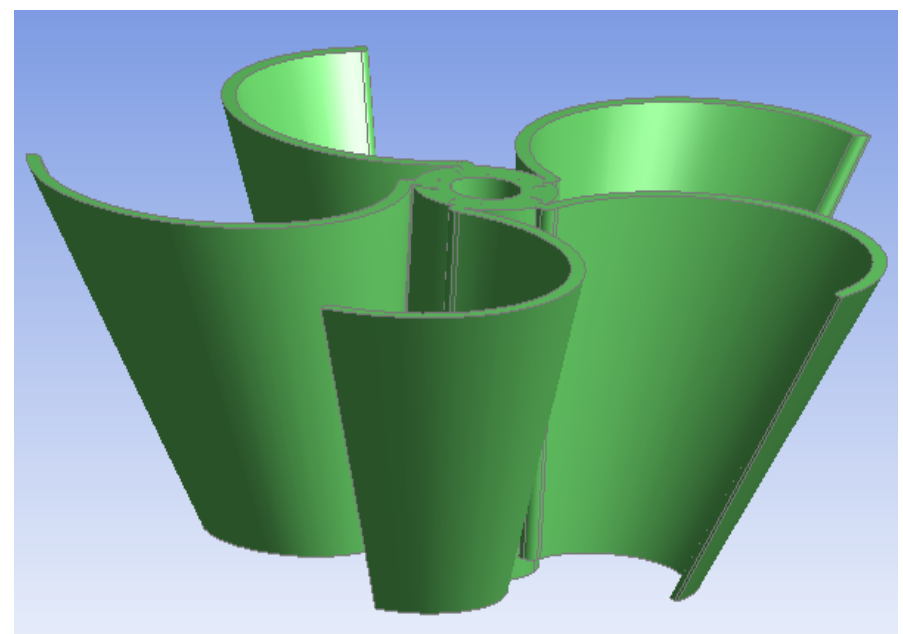

Figure 6: Proposed Novel runner of GWVPP.

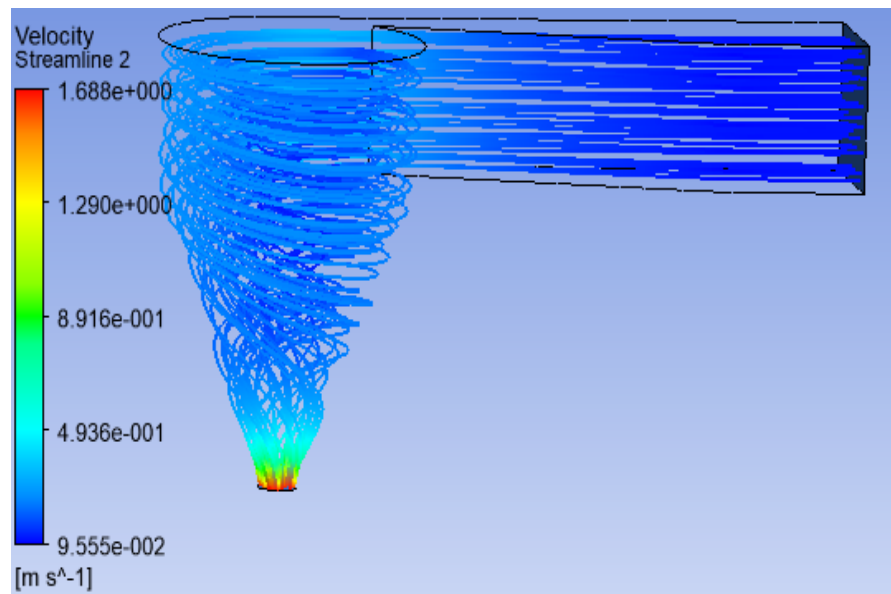

Figure 7: Velocity streamlines analysis of GWVPP Model with inside novel runner.

\section{Experimental procedure}

A rectangular water tank $30-\mathrm{cm}$ height and $40-\mathrm{cm}$ width and $60 \mathrm{~cm}$ length have been fabricated for experiments. A pulley was connected with the top of output shaft, which linked further with spring balances. The radius of a pulley is $30 \mathrm{~mm}$. Prony brake mechanism has used to measure the brake force on output shaft in which spring balances were used to measure the net force on output shaft. The torque absorbed on output shaft was calculated when net force measured through spring balances was multiplied to the pulley radius. The ball bearing was used to supported the output shaft for accurate measurement of torque and rotational speed $(\mathrm{N})$ of a turbine. The digital tachometer is used to measure the rotational speed in revolutions per minute (rpm). The experimental set up and schematic set up of GWVPP were as shown in Figures 8 and 9.

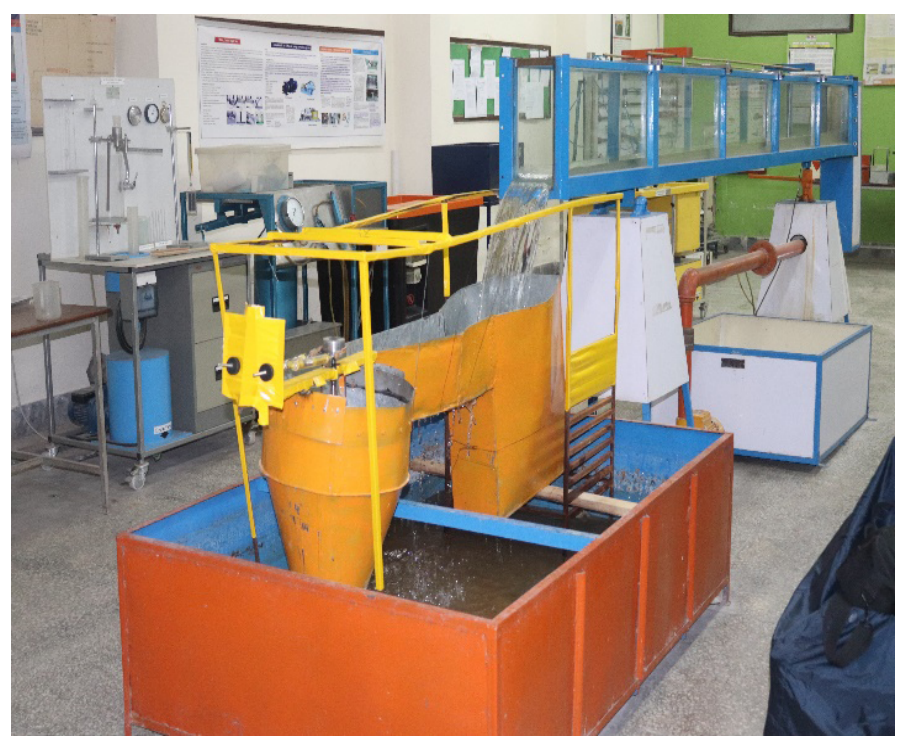

Figure 8: Experimental set up of GWVPP Model.

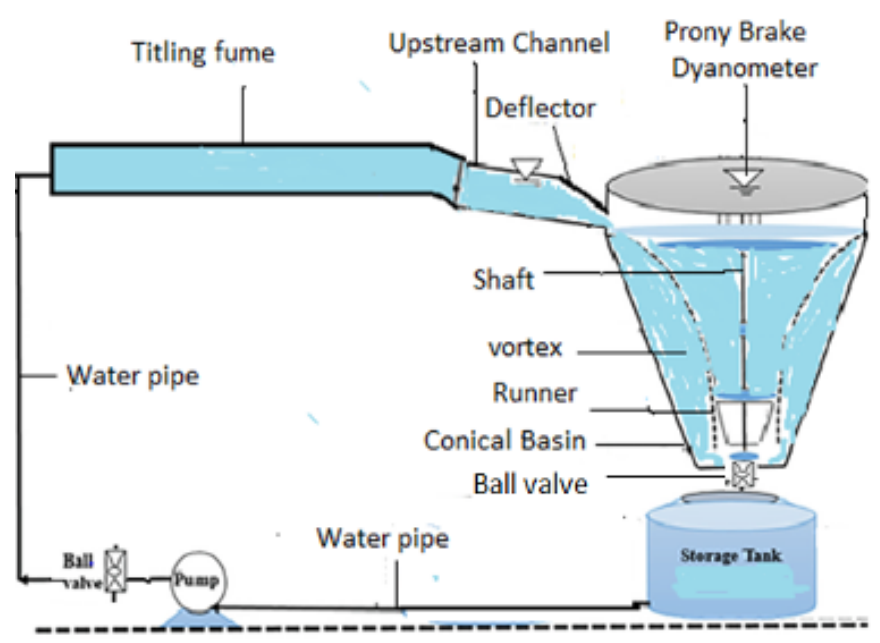

Figure 9: Schematic of GWVPP Set up.

From below Table $1 F_{1}$ is the extension force and $F_{2}$ is the compression force produced due to force applied on turbine shaft. Net force came from extension force compression force. The spring balances were used to measure the net force on the output shaft. This net force deliberated by the spring balances, when multiplied with pulley radius gives the torque applied on the shaft as shown in Table 1.

\section{Results and Discussion}

At low torque turbine rotate at higher speed. As shown in Figure 10, torque on Turbine increases RPM of vortex turbine decreased which produced low water vortex hence to produce low output. 
Table 1: Experimental reading of novel runner inside conical basin.

\begin{tabular}{|c|c|c|c|c|c|c|c|c|c|c|}
\hline \multirow{2}{*}{$\begin{array}{l}\text { Run } \\
\text { order }\end{array}$} & \multicolumn{4}{|c|}{ Torque measurement } & \multicolumn{3}{|c|}{ Power input (watt) } & \multicolumn{2}{|c|}{ Power output } & \multirow{2}{*}{$\begin{array}{l}\text { Efficien- } \\
\text { cy (n) }\end{array}$} \\
\hline & $\mathrm{F}_{1}(\mathrm{~N})$ & $\mathrm{F}_{2}(\mathrm{~N})$ & Net force $(\mathrm{N})$ & Torque (N-m) & Head (m) & Flow rate $(\mathrm{Q})$ & Pin (Watt) & W (rpm) & Pout. (Watt) & \\
\hline 1 & 10 & 4 & 6 & 0.18 & 0.6 & 0.002 & 11.72 & 230 & 4.33 & 36.94 \\
\hline 2 & 14 & 6.3 & 7.7 & 0.231 & 0.6 & 0.002 & 11.72 & 205 & 4.95 & 42.23 \\
\hline 3 & 15 & 5 & 10 & 0.3 & 0.6 & 0.002 & 11.72 & 183 & 5.74 & 48.97 \\
\hline 4 & 17 & 5 & 12 & 0.36 & 0.6 & 0.002 & 11.72 & 164 & 6.17 & 52.64 \\
\hline 5 & 19 & 6.5 & 12.5 & 0.375 & 0.6 & 0.002 & 11.72 & 152 & 5.96 & 50.85 \\
\hline 6 & 21 & 8.3 & 12.7 & 0.381 & 0.6 & 0.002 & 11.72 & 137 & 5.46 & 46.58 \\
\hline 7 & 25 & 12.1 & 12.9 & 0.387 & 0.6 & 0.002 & 11.72 & 126 & 5.10 & 43.51 \\
\hline 8 & 25 & 12 & 13 & 0.39 & 0.6 & 0.002 & 11.72 & 116 & 4.73 & 40.35 \\
\hline 9 & 28 & 12 & 16 & 0.48 & 0.6 & 0.002 & 11.72 & 82 & 4.11 & 35.06 \\
\hline 10 & 28.5 & 11.5 & 17 & 0.52 & 0.6 & 0.002 & 11.72 & 73 & 3.89 & 33.19 \\
\hline
\end{tabular}

Power output of GWVPP gradually increased with increased in torque but decreased when higher torque applied on vortex turbine. As from below Figure 11 power output is maximum at medium torque applied on vortex turbine and low at higher torque. Power output is low at higher torque $0.52(\mathrm{~N}-\mathrm{m})$ and maximum at $0.36(\mathrm{~N}-\mathrm{m})$ i.e. at median torque.

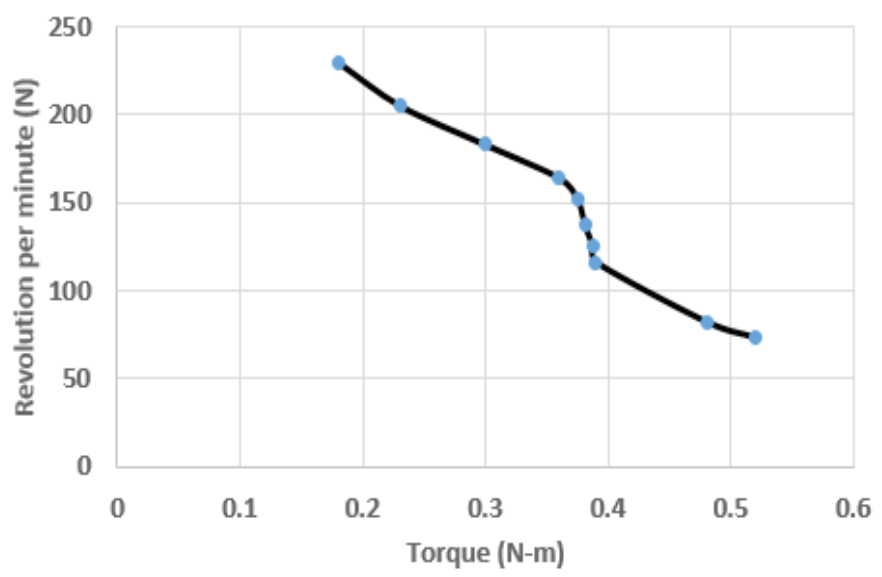

Figure 10: Torque vs Revolution per minute $(N)$.

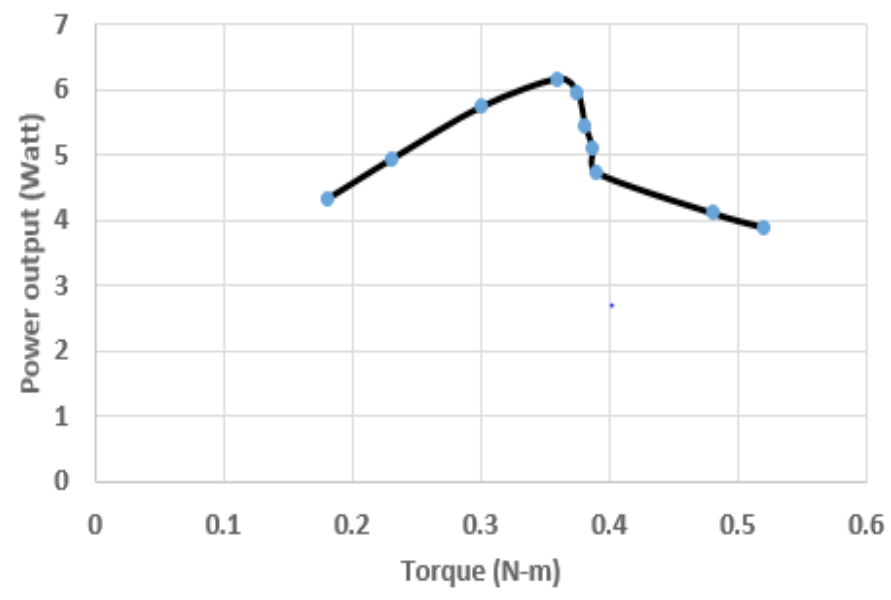

Figure 11: Torque vs power output (Watt).

As efficiency of turbine depend on output power.
As output power of vortex turbine is maximum at medium torque, so efficiency is also maximum at medium of torque. From below Figure 12 it showed that efficiency increased with increased in torque up to certain limit then decreased at higher torque also efficiency is maximum at $0.36(\mathrm{~N}-\mathrm{m})$ i.e. median torque but low at $0.52(\mathrm{~N}-\mathrm{m})$ torque.

Output power is torque multiply rpm. As torque increased turbine rotate at low speed which enhanced low power output, at medium rotational speed of turbine, the vortex turbine has maximum efficiency. As from below Figure 13 it showed that at 164 i.e. median rpm the turbine has maximum output and low output at 250 i.e. higher rpm.

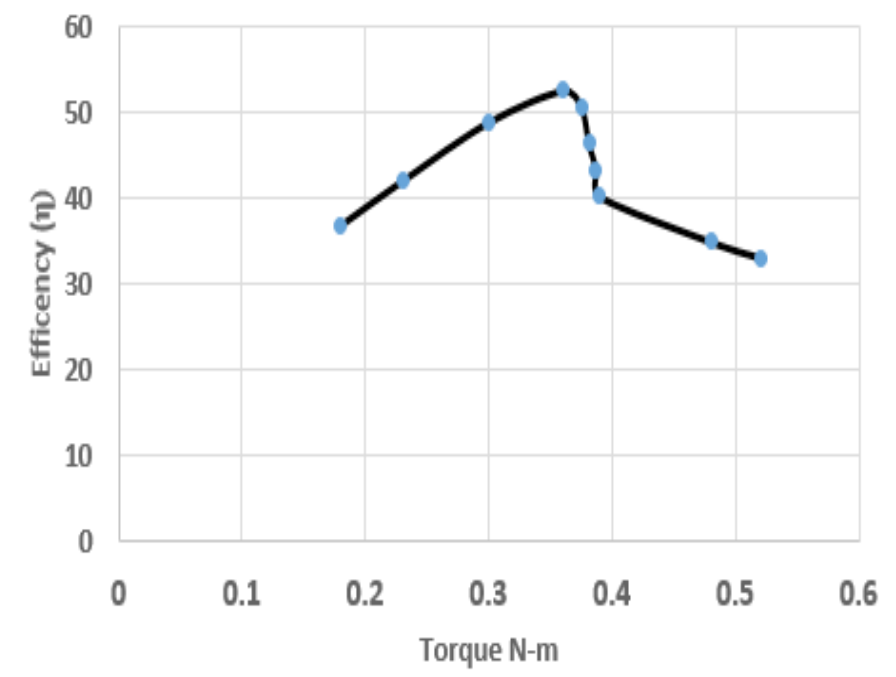

Figure 12: Torque vs efficiency.

Water Vortex height decreased with increased in torque applied on output shaft. From below Figure 14 it showed that vortex height decreased gradually as torque increased. 


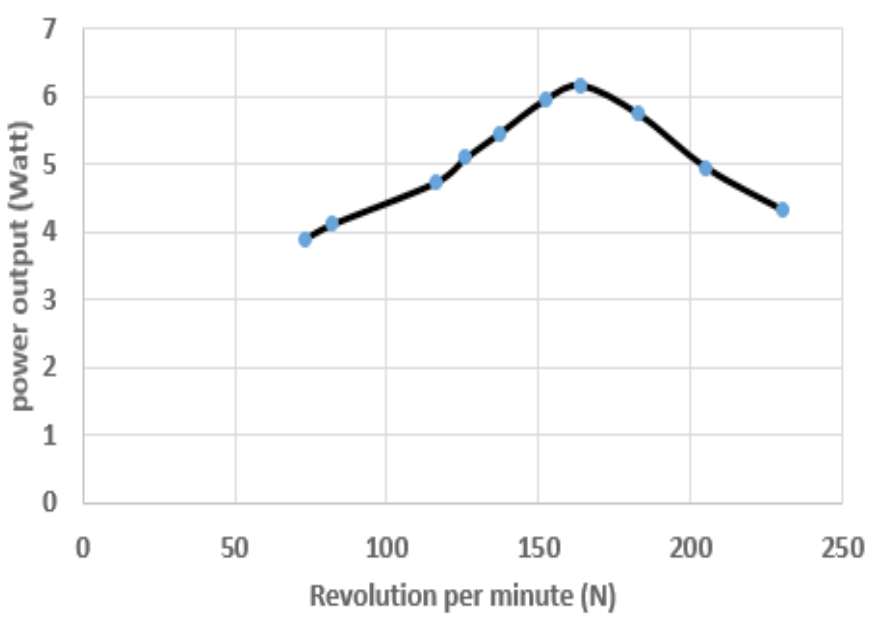

Figure 13: Revolution per minute $(N)$ vs power output (Watt).

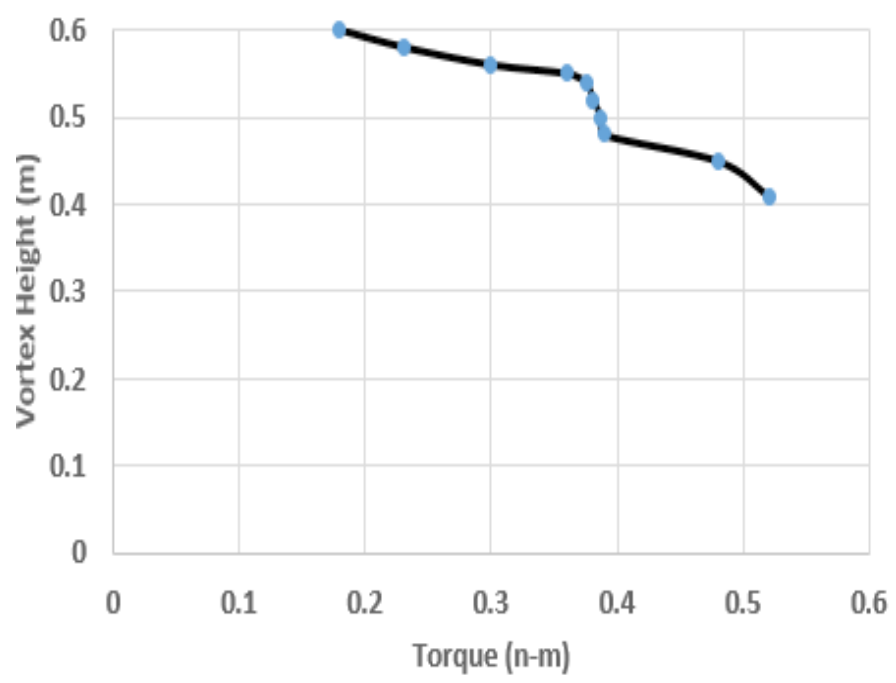

Figure 14: Torque $(n-m)$ vs vortex height.

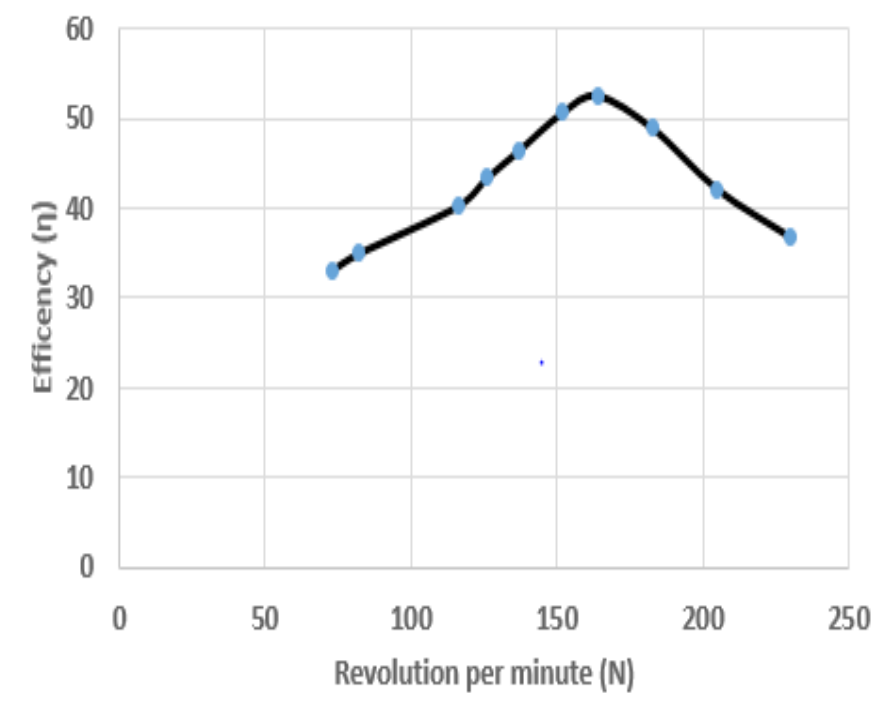

Figure 15: Revolution per minute $(N)$ vs efficiency.

Efficiency increased with increased in rotational speed of turbine but decreased at low and higher rpm. As from Figure 15 efficiency is maximum at $164 \mathrm{rpm}$ i.e. median rpm and low at 73 i.e. higher rpm. At medium rpm the vortex turbine showed maximum efficiency.

\section{Conclusions and Recommendations}

The GWVPP hydropower could be the appropriate choice to off-grid and rural electrification area of Pakistan. Low hydropower like (GWVPP) plays a significant aspect in contributing electricity to rural and mountainous areas of Pakistan. In the above study, an experimental analysis should have investigated on novel runner i.e. curved blade profile of gravitational water vortex power plant. The output parameters such as torque, rotational speed, output power, and efficiency had been investigated for a novel runner. It showed that novel runner showed maximum efficiency of $(52.64 \%)$ at $2 \mathrm{~L} / \mathrm{s}$ of water flow rate. and output shaft power and efficiency is maximum at median rotational speed (rpm) and median torque applied on shaft. Also vortex height of GWVPP decreased when torque increased.

\section{Novelty Statement}

In previous literatures straight and half curved runner were designed for GWVPP which produced low output power and efficiency. In current research work, novel runner shape is designed for GWVPP which produced efficient micro hydro power generation and maximize the efficiency of Gravitational water vortex turbine assembled in a conical basin.

\section{Author's Contribution}

Aamer Sharif: Conceptualization, development,modeling, simulation, experimentations and analysis. Muftooh Ur Rehman Siddiqi: Supervision, guidelines, investigation, delivered resources.

Riaz Muhammad: Supervision, provided testing facility.

\section{Conflict of interest}

The authors have declared no conflict of interest.

\section{References}

Chattha, J.A., T.A. Cheema, et al. 2017. Numerical investigation of basin geometries for vortex generation in a gravitational water vortex power plant. $20178^{\text {th }}$ Int. Renewable Energy Cong. (IREC), IEEE. https://doi.org/10.1109/ 
IREC.2017.7926028

Dhakal, S., A.B. Timilsina, et al. 2015. Comparison of cylindrical and conical basins with optimum position of runner: Gravitational water vortex power plant. Renewable and Sustainable Energy Rev., 48: 662-669. https://doi.org/10.1016/j. rser.2015.04.030

Dhakal, S., A.B. Timilsina, et al. 2015. Mathematical modeling, design optimization and experimental verification of conical basin: Gravitational water vortex power plant. dalam World Largest Hydro Conference.

Dhakal, S., S. Nakarmi, et al. 2014. Development and testing of runner and conical basin for gravitational water vortex power plant. J. Inst. Eng., 10(1): 140-148. https://doi.org/10.3126/ jie.v10i1.10895

Gautam, A., A. Sapkota, et al. 2016. Study on effect of adding booster runner in conical basin: gravitational water vortex power plant: a numerical and experimental approach. Proceedings of IOE graduate conference.

Gheorghe-Marius, M. and S. Tudor. 2013. Energy capture in the gravitational vortex water flow. J. Mar. Technol. Environ. pp. 1.

Khan, N.H., T.A. Cheema, et al. 2018. Effective basin blade configurations of a gravitational water vortex turbine for microhydropower generation. J. Energy Eng. 144(4): 04018042. https://doi.org/10.1061/(ASCE)EY.19437897.0000558

Li, H.-f., H.-x. Chen, et al. 2008. Experimental and numerical investigation of free surface vortex. J. Hydrodyn. 20(4): 485-491. https://doi. org/10.1016/S1001-6058(08)60084-0

Mulligan, S. and P. Hull. 2010. Design and optimisation of a water vortex hydropower plant. Undergraduate thesis, Inst. of Tech. Sligo, Sligo, Ireland.

Nishi, Y. and T. Inagaki. 2017. Performance and flow field of a gravitation vortex type water turbine. Int. J. Rotat. Mach., 2017. https://doi. org $/ 10.1155 / 2017 / 2610508$
Power, C., A. McNabola, et al. 2016. A parametric experimental investigation of the operating conditions of gravitational vortex hydropower (GVHP). J. Clean Energy Technol., 4(2): 112119. https://doi.org/10.7763/JOCET.2016. V4.263

Rahman, M., J. Tan, et al. 2017. A review on the development of gravitational water vortex power plant as alternative renewable energy resources. IOP conference series: Materials science and engineering, IOP Publishing. https://doi. org/10.1088/1757-899X/217/1/012007

Rizwan, Cheema et al. 2020. Preliminary experimental study on multi stage gravitational water vortex turbine in a conical basin. Renewable Energy, pp. 0960-1481.

Shabara, H., O. Yaakob, et al. 2015. CFD validation for efficient gravitational vortex pool system. J. Teknol. 74(5). https://doi.org/10.11113/ jt.v74.4648

Venukumar,A.,2013.Artificial vortex (ArVo) power generation, An innovative micro hydroelectric power generation scheme. 2013 IEEE global humanitarian technology conference: South Asia Satellite (GHTC-SAS), IEEE. https:// doi.org/10.1109/GHTC-SAS.2013.6629888

Wanchat,S.and R.Suntivarakorn.2012.Preliminary design of a vortex pool for electrical generation. Adv. Sci. Lett. 13(1): 173-177. https://doi. org/10.1166/asl.2012.3855

Wang, Y.-k., Jiang, C.-b., and Liang, D.-f. 2010. Investigation of air-core vortex at hydraulic intakes. J. Hydrodyn., 673-678.

Wanchat, S., R. Suntivarakorn, et al. 2013. A parametric study of a gravitation vortex power plant. Advanced Materials Research, Trans Tech Publ. https://doi.org/10.4028/www. scientific.net/AMR.805-806.811

Wichian, P. and R. Suntivarakorn. 2016. The effects of turbine baffle plates on the efficiency of water free vortex turbines. Energy Procedia, 100: 198-202. https://doi.org/10.1016/j. egypro.2016.10.165 